Journal of Clinical Investigation
Vol. 42, No. 9,1963

\title{
MECHANICAL PROPERTIES OF LUNG IN NORMAL MEN OVER 60 YEARS OLD *
}

\author{
By J. E. COHN † AND H. D. DONOSO
}

(From the Department of Medicine, University of Utah College of Medicine, and the Pulmonary Laboratory, Veterans Administration Hospital, Salt Lake City, Utah)

(Submitted for publication August 20, 1962; accepted May 17, 1963)

There are conflicting reports concerning the effects of aging on mechanical properties of the human respiratory system (1-4). The present study was undertaken to collect additional information pertaining to the relationships between normal aging and lung mechanics. Besides the mechanics measurements, data are reported for lung volumes, intrapulmonary gas mixing, and ventilatory capacity.

\section{METHODS}

Nineteen subjects over 60 years old were selected who a) were free from complaints referable to cardiac, pulmonary, or neuromuscular systems; $b$ ) had normal physical examinations; and $c$ ) demonstrated normal chest roentgenograms and electrocardiograms. These men constitute group I subjects. Similar criteria were applied in selection of 13 men under 40 who comprised group II. Eight older men and six of the younger were cigarette smokers. Physical characteristics of the two groups are shown in Table I.

Spirograms were recorded with a 13.5 L Collins ${ }^{1}$ spirometer from which all valves had been removed. A closed-circuit, constant-volume, helium $(\mathrm{He})$-dilution method was used to measure the functional residual capacity (FRC) in seated subjects. Lung compartments and their ratios were calculated. Intrapulmonary distribution of inspired gas was evaluated by the $\mathrm{N}_{2}$, singlebreath test (5).

The dynamic lung compliance $\left(\mathrm{C}_{\mathrm{dyn}}\right)$ was determined by the methods of Mead and Whittenberger (6). Mouth-esophageal pressure gradients were detected by a differential pressure transducer. ${ }^{2}$ The signal was amplified and displayed on the horizontal axis of a cathoderay oscilloscope ${ }^{3}(\mathrm{CRO})$. Flow rates were measured

* Supported in part by U. S. Public Health Service grant B-1220. Previously published as an abstract: Clin. Res. 1961, 9, 195.

$\dagger$ Present address: Department of Medicine, College of Medicine, University of Kentucky, Lexington, $\mathrm{Ky}$.

$\ddagger$ Present address: Escuela de Medicina, Laboratorio de Fisiopatologia, Universidad de Chile, Casilla 6510, Santiago, Chile.

1 Warren E. Collins, Inc., Boston, Mass.

2 Statham Instruments, Los Angeles, Calif.

3 Tektronix, Beaverton, Oreg. with a pneumotachograph, ${ }^{4}$ and tidal volume was obtained by electronic integration of the flow signal. Flow, or volume, or both, were exhibited on the vertical axis of the CRO. From simultaneous displays of mouthesophageal pressure and volume signals, pressure-volume loops were recorded. An electronic subtractor circuit was employed to obtain $C_{d y n}$ (7). Each compliance value recorded represented the mean of at least 10 determinations. $C_{d y n}$ was measured under three separate sets of conditions: (a) normal quiet breathing, $(b)$ at tidal volumes equivalent to normal breathing but with increased respiratory frequency, and $(c)$ at tidal volumes about twice normal and relatively slow frequency. The static transpulmonary pressure gradient achieved during sustained full lung inflation, referred to as maximal inspiratory pressure (MIP), was also recorded for each subject.

TABLE I

Physical characteristics of subjects

\begin{tabular}{lcc}
\hline \hline & Group I & Group II \\
\hline Mean age, yrs. & $76(60-82)$ & $33(28-40)$ \\
Mean height, $i$. & $66(64-73)$ & $68(66-76)$ \\
Mean weight, $l b s$. & $166(117-226)$ & $169(140-191)$ \\
Mean body surface area, $m^{2}$ & $1.89(1.55-2.26)$ & $1.92(1.75-2.17)$ \\
Number & 19 & 13 \\
\hline
\end{tabular}

The volume of thoracic gas $\left(\mathrm{V}_{\mathrm{TG}}\right)$ and airway resistance $(R)$ was determined with a body plethysmograph (8), employing techniques described by Comroe, Botelho, and DuBois (9). Resistance was measured at airflow velocities of $1 \mathrm{~L}$ per second for several levels of lung inflation. Airway conductance $(I / R=C)$ was computed according to Briscoe and DuBois (10). Total lung resistance was not measured.

\section{RESULTS}

Lung compartments, ventilatory function, intrapulmonary gas mixing (Table II). Vital capacity (VC) and inspiratory capacity (IC) were significantly larger in the younger men $(\mathrm{p}<.01)$, whereas FRC, residual volume (RV), and residual volume/total lung capacity ratios $(\mathrm{RV} / \mathrm{TC}$ $\times 100)$ were significantly greater $(p<.001)$ in

${ }^{4}$ Electronics for Medicine, White Plains, N. Y. 
the old men. Differences between mean total lung volumes in the two groups were not statistically significant. Ventilatory capacity (MBC) and maximal midexpiratory flow rate (MMF) (13) were decreased in older subjects. The distribution of inspired gas, evaluated by the single-breath nitrogen test, was less uniform in older men than in younger ones.

FRC, determined by the $\mathrm{He}$ method in a seated subject, corresponds to $V_{\text {TG }}$ measured with the plethysmograph at the end of quiet exhalation. FRC and $\mathrm{V}_{\mathrm{TG}}$ determinations were in close agreement in each group. The maximal discrepancy between volumes measured by these two different techniques in a given subject was less than $350 \mathrm{ml}$. For this report, He determinations were used to compute lung compartments and TC. FRC and RV measurements are larger than those usually recorded (14-17) because subjects were seated rather than supine during the determinations.

Respiratory mechanics (Tables III, IV). Three arbitrary sets of conditions were utilized during measurements of $\mathrm{C}_{\mathrm{dyn} n}$. The first determinations, designated $\mathrm{C}_{\mathrm{dyn}(\mathrm{a})}$, were made during normal quiet breathing. During these performances, group II subjects exhibited slower frequencies and slightly smaller mean volumes than group I. Mean $C_{d y n(a)}$ for group I was significantly higher than for group II.

The effect of increased frequency on $C_{d y n}$ values

TABLE II

Lung compartments, ventilatory function, and intrapulmonary gas mixing*

\begin{tabular}{|c|c|c|c|}
\hline & Group I & Group II & $\begin{array}{l}\text { Group I vs } \\
\text { Group II }\end{array}$ \\
\hline VC, $L$ & $4.39 \pm 0.55 \dagger$ & $4.96 \pm 0.47$ & $3.05 \ddagger$ \\
\hline IC, $L$ & $3.13 \pm 0.37$ & $3.61 \pm 0.28$ & $3.93 \S$ \\
\hline FRC, $L,(\mathrm{He})$ & $4.47 \pm 0.80$ & $3.26 \pm 0.31$ & $5.17 \S$ \\
\hline $\begin{array}{l}\mathrm{V}_{\mathrm{TG}} \text { (mid-position), } L, \\
\text { plethysmograph }\end{array}$ & $4.60 \pm 0.91$ & $3.50 \pm 0.42$ & \\
\hline $\mathrm{RV}, L$ & $2.88 \pm 0.56$ & $1.97 \pm 0.46$ & 4.68 \\
\hline TC, $L$ & $7.32 \pm 0.85$ & $6.89 \pm 0.61$ & 1.57 \\
\hline $\mathrm{RV} / \mathrm{TC} \times 100$ & $39 \pm 5$ & $28 \pm 6$ & 4.628 \\
\hline $\mathrm{MBC}, L / \min$ & $122 \pm 25$ & $207 \pm 21$ & $10.1 \S$ \\
\hline MMF, L/sec. & $2.88 \pm 0.65$ & $4.41 \pm 0.31$ & 7.678 \\
\hline $\begin{array}{r}\text { Change in } \mathrm{N}_{2} \% \\
V_{E} 750-1,250\end{array}$ & $2.3 \pm 0.8$ & $1.34 \pm 0.4$ & $4.15 \S$ \\
\hline
\end{tabular}

* VC = vital capacity; IC = inspiratory capacity $\quad \mathrm{FRC}=$ functional residual capacity; $V_{T G}=$ volume of thoracic gas; $R V=$ residual volume; $\mathrm{TC}=$ total lung capacity; $\mathrm{MBC}=$ ventilatory capacity ; Standard symbols (11); statistical methods (12).

$\dagger$ Mean \pm standard deviation.

$\ddagger$
$\mathrm{p}<.01$
TABLE III

Respiratory mechanics measurements

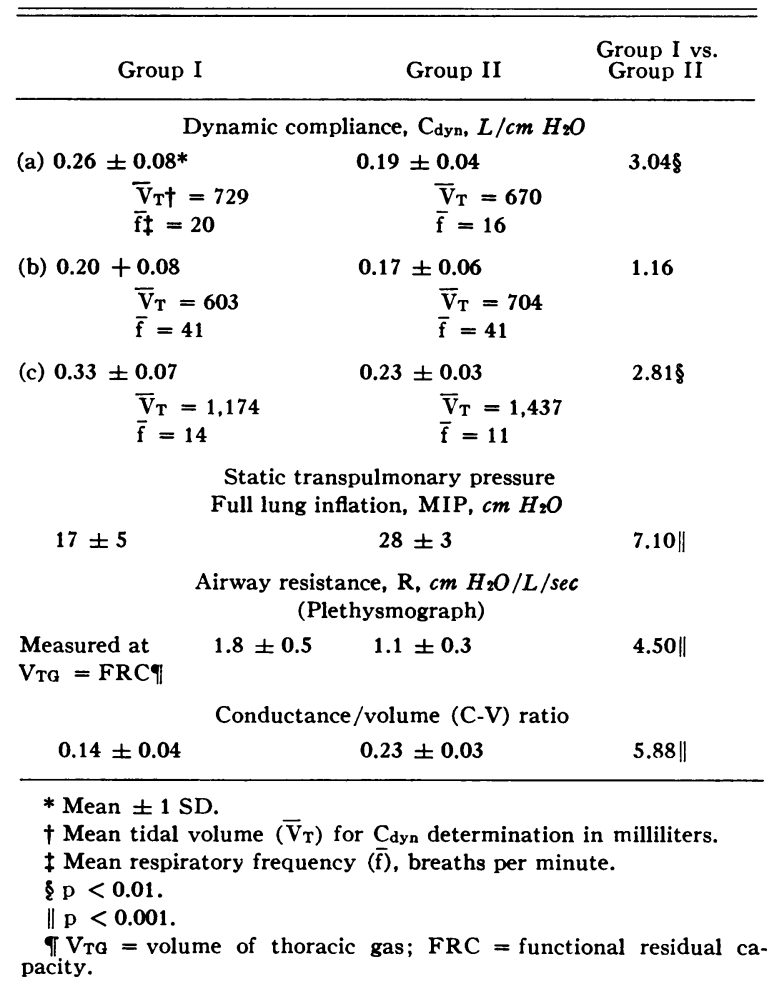

was examined, $\mathrm{C}_{\mathrm{dyn}(\mathbf{b})}$. Tidal volumes were voluntarily maintained at or near those employed for spontaneous breathing, and frequency was doubled. During these tests, mean frequencies in both groups were the same, but the mean tidal volumes in group I were $14.5 \%$ smaller than in group II. Differences of mean $C_{d y n(b)}$ between groups were not significant.

Finally, the influence of large tidal volumes and normal or slow frequencies in $\mathrm{C}_{\mathrm{dyn}}$ was analyzed, $\mathrm{C}_{\mathrm{dyn}(\mathbf{c})}$. The older men achieved significantly larger mean $\mathrm{C}_{\mathrm{dyn}(\mathrm{e})}$ values than did the younger ones.

Mean $\mathrm{C}_{\mathrm{dyn}}$ decreased significantly when respiratory frequency was doubled in group I subjects. No comparable change occurred in group II. Slow, deep breathing produced a rise of mean $\mathrm{C}_{\mathrm{dyn}}$ in the older men. $\mathrm{C}_{\mathrm{dyn}(\mathrm{c})}$ was larger than either $\mathrm{C}_{\mathrm{dyn(a)}}$ or $\mathrm{C}_{\mathrm{dyn}(\mathbf{b})}$ in group I subjects. For group II subjects, $\mathrm{C}_{\mathrm{dyn}(\mathrm{c})}$ was not different from (a) but was greater than (b)..$^{5}$

${ }^{5}$ Tests of these differences are based on determination of a "least significant difference" using pooled estimates of variance $(12)$. 
TABLE IV

Regression relationships of maximal static transpulmonary pressures in group I subjects*

\begin{tabular}{llcc}
\hline \hline Relationship & Linear regression & $\begin{array}{c}\text { Standard error } \\
\text { of slope }\end{array}$ & Correlation \\
\hline MIP and VC & MIP $=18.22-0.187 \mathrm{VC}$ & 2.22 & -0.02 \\
MIP and C & 14.18 & -0.28 \\
MIP and RV/TC & MIP $=22.02-17.76 \mathrm{C}_{\text {dyn(a) }}$ & 0.21 & -0.28 \\
MIP and FRC & MIP $=27.35-0.253 \mathrm{RV} / \mathrm{TC}$ & $1.01 \dagger$ & -0.50 \\
\hline
\end{tabular}

${ }^{*} \mathrm{MIP}=$ maximal inspiratory pressure $; \mathrm{VC}=$ vital capacity $; \mathrm{C}_{\mathrm{dyn}(\mathrm{a})}=$ dynamic lung compliance at normal quiet breathing; $\mathrm{RV} / \mathrm{TC}=$ residual volume/total lung capacity ratio; $\mathrm{FRC}=$ functional residual capacity.

$\dagger$ Slope significantly different from zero at $5 \%$ level.

Transpulmonary pressure gradients at full lung inflation (MIP) were larger (i.e., more negative) in the young men, and differences between groups were highly significant. The validity of an MIP value depends upon the subject understanding the test and co-operating to the best of his ability. Each value reported was reproducible on several occasions. Pressures were recorded and measurements taken after pressure tracings had been stable for 4 seconds. Table IV records regression equations defining relationships between MIP and several other measurements for group I subjects. The slope of regression between MIP and FRC is the only one significantly different from zero.

Mean $\mathrm{R}$, determined in the plethysmograph at $\mathrm{V}_{\text {TG }}$ equivalent to FRC and $1 \mathrm{~L}$ per second flow, was higher in the older subjects. The calculation of airway conductance $(1 / R)$ and its relationship to $\mathrm{V}_{\mathrm{TG}}$-conductance/volume ratio $(\mathrm{C} / \mathrm{V})$ - permits comparisons between individuals or groups. $\mathrm{C} / \mathrm{V}$ ratios in group I were significantly smaller than in group II, and there was no overlap between the groups.

\section{DISCUSSION}

$\mathrm{C}_{\mathrm{dyn}}$ during spontaneous respiration was significantly greater in the older subjects than in the younger ones. This alteration in compliance may account for all of the alterations in respiratory mechanics, lung compartments, and intrapulmonary mixing that we and others have observed in suljects of advanced age.

The dimensions and spatial relationships of terminal and respiratory bronchioles, alveolar ducts, and alveoli are maintained, in part, by interlacing fibers of the lung elastic matrix. At any level of lung inflation, the elastic tensions devel- oped within the lung matrix decrease as the compliance rises. Airways of comparable size and structure, being subjected to smaller radial tensions, are therefore less distended in lungs with higher compliance. This results in smaller intraluminal diameters of these airways and increased resistance to flow through them, compared to less compliant lungs at comparable inflation volumes $(18,19)$. An inverse relationship thus exists between compliance and airflow resistance in lungs at any given inflation volume.

It is suggested that alterations in the elastic matrix, causing increased compliance in the older men, are distributed unevenly, perhaps at random, through the lungs. Their lungs may be considered as being composed of populations of units (acini or lobules) with nonuniform pressurevolume characteristics. In such organs, the alveolar volume into which tidal breaths are dispersed can vary with respiratory rate, tidal volume, and lung inflation. During rapid breathing, groups of units may not be fully functional because of long time constants and $\mathrm{C}_{\mathrm{dyn}}$ decreases (20). Rapid respiratory frequency did not produce a significant change of $\mathrm{C}_{\mathrm{dyn}}$ in our younger men, nor has $\mathrm{C}_{\mathrm{d} y \mathrm{n}}$ been reported by others to vary with respiratory frequency in young normal subjects $(20,21)$. Conversely, in lungs with high compliance, slow, deep respiration permits the tidal volume to be distributed to a larger volume. and $\mathrm{C}_{\mathrm{d} y n}$ rises. This is suggestive of and compatible with "recruitment of units" $(21,22)$. A similar but smaller change was present in the young men. This phenomenon has been reported in normal individuals (23) and subjects with chronic diffuse obstructive airway diseases (24, 25 ). It is concluded that all observed differences of $\mathrm{C}_{\mathrm{dyn}}$ measurements between the two groups in 
tine present report can be accounted for by the presence of focal areas of increased compliance and decreased conductance in the lungs of older men. As Mead wrote $(26), \mathrm{C}_{\mathrm{d} y n}$ values are influenced by lung compliance, lung inflation, respiratory rate, and airflow resistance.

Additional evidence for increased lung compliance in the older men is afforded by the static transpulmonary pressures measured at full inflation. Since total lung volumes were not significantly different between the two groups, comparable transpulmonary pressures should be generated by lungs with similar elastic recoil. The observed differences indicate that less elastic tension occurred in the older subjects, so their lungs were more compliant. It may be argued that this measurement could be influenced by thoracic bellows strength. Subjects with muscular dystrophy and chest wall weakness, however, produced normal values for this test (27). Overt thoracic bellows weakness was not present in our elderly men. Milic-Emili, Glauser, and Mead (28) analyzed artifacts in the determination of transpulmonary pressure at full lung inflation by the technique employed here. Our data are considered satisfactory for comparison because identical balloons and procedures were used in all subjects. The effects of intrathoracic gas volume on balloon volumes and esophageal elastance are considered equivalent because mean total lung volumes were not different for the two groups. One factor that may have affected the measurement, changes of esophageal compliance with age, was not evaluated.

The larger FRC volumes in the older men constitute further evidence for increased lung compliance in that group. Similar pulmonary retractile forces affect both FRC and MIP values, and it is interesting to note a significant negative correlation between these measurements (Table IV).

If the postulated relationships between compliance and airway diameters are valid, ventilatory measurements influenced by airway conductance should be lower in the elderly. The lower MBC and MMF values and the smaller $\mathrm{C} / \mathrm{V}$ ratios observed support the basic thesis. Focal areas of altered compliance and conductance could produce abnormalities of intrapulmonary mixing. The less even distribution of in- spired gas in group I subjects is indirect evidence for the presence of such regional changes in the lungs of older men.

Pierce and Ebert (2) reported decreased elasticity in the lungs of older subjects. Permutt and Martin (3), using different techniques, observed no significant change in static lung compliance $\left(C_{L}\right)$ with age. Their older subjects did not exhibit increased FRC volumes. However, diminished elastic recoil at TC was found in older people. Frank, Mead, and Ferris (1) also found no differences in static $C_{L}$ in elderly subjects. Again, their young subjects achieved greater transpulmonary pressures at full lung inflation. No consistent change of $\mathrm{C}_{\mathrm{dyn}}$ with age was reported. However, $72 \%$ of their subjects were female. All subjects in the present study were males. The possible influence of sex on aging processes may be the basis for dissimilarities between our data and those of Frank and associates (1). Greifenstein, King, Latch, and Comroe (29) found intrapulmonary mixing to be much more uneven in normal elderly males than elderly females. Needham, Rogan, and McDonald (1) make this comment: "It is interesting to note how much more kindly the years treat the women in respect to both VC and MBC." Differing patterns of pulmonary disease observed between males and females may be related to the manner in which normal aging affects the elastic properties of the lung for each sex.

\section{SUM M ARY}

Mechanical properties of lungs in normal men over 60 years old were compared to normal men under 40. Dynamic lung compliance was significantly greater in the older subjects. Transpulmonary pressures at full lung inflation were greater in the younger group. Airway resistance was higher and conductance/volume ratios were lower in the older men. Changes of pulmonary physiological parameters with age in men may be secondary to increased pulmonary compliance in the elderly.

\section{ACKNOWLEDGMENT}

Dr. Alan Ross, Department of Behavioral Science, University of Kentucky Medical Center, provided statistical consultation. 


\section{REFERENCES}

1. Frank, N. R., J. Mead, and B. G. Ferris, Jr. The mechanical behavior of the lungs in healthy elderly subjects. J. clin. Invest. 1957, 36, 1680.

2. Pierce, J. A., and R. V. Ebert. The elastic properties of the lungs in the aged. J. Lab. clin. Med. 1958, 51, 63.

3. Permutt, S., and H. B. Martin. Static pressure-volume characteristics of lungs in normal males. J. appl. Physiol. 1960, 15, 819.

4. Ehrner, L. Lung compliance and respiratory resistance, determined from time-marked esophageal pressure-tidal volume curve and their relation to some other tests of lung function. Acta med. scand. 1960, 167 (suppl.), 353.

5. Comroe, J. H., Jr., and W. S. Fowler. Lung function studies. VI. Detection of uneven alveolar ventilation during a single breath of oxygen. Amer. J. Med. 1951, 10, 408.

6. Mead, J., and J. L. Whittenberger. Physical properties of human lungs measured during spontaneous respiration. J. appl. Physiol. 1953, 5, 779.

7. Miller, J. H., and D. H. Simmons. Rapid determination of dynamic pulmonary compliance and resistance. J. appl. Physiol. 1960, 15, 967.

8. Schmidt, A. M., and J. E. Cohn. Modified body plethysmograph for study of cardiopulmonary physiology. J. appl. Physiol. 1961, 16, 935.

9. Comroe, J. H., Jr., S. Y. Botelho, and A. B. DuBois. Design of a body plethysmograph for studying cardiopulmonary physiology. J. appl. Physiol. 1959, 14, 439.

10. Briscoe, W. A., and A. B. DuBois. The relationship between airway resistance, airway conductance and lung volume in subjects of different age and body size. J. clin. Invest. 1958, 37, 1279.

11. Standardization of definitions and symbols in respiratory physiology, J. R. Pappenheimer, Committee Chairman. Fed. Proc. 1950, 9, 602.

12. Snedecor, G. W. Statistical Methods, 5th ed. Ames, Iowa State College Press, 1956.

13. Leuallen, E. C., and W. S. Fowler. Maximal midexpiratory flow. Amer. Rev. Tuberc. 1955, 72, 783.

14. Kaltreider, N. L., W. W. Fray, and H. V. Z. Hyde. The effect of age on the total pulmonary capacity and its subdivisions. Amer. Rev. Tuberc. 1938, 37,662 .

15. Needham, C. D., M. C. Rogan, and I. McDonald. Normal standards for lung volumes, intrapul- monary gas mixing, and maximum breathing capacity. Thorax 1954, 9, 313.

16. Carpenter, R. G., A. L. Cochrane, J. C. Gilson, and I. T. Higgins. The relationship between ventilatory capacity and simple pneumoconiosis in coal workers. Brit. J. industr. Med. 1956, 13, 166.

17. Norris, A. H., N. W. Shock, M. Landowne, and J. A. Falzone, Jr. Pulmonary function studies: age differences in lung volumes and bellows function. J. Geront. 1956, 11, 379.

18. Fry, D. L. Theoretical considerations of the bronchial pressure-flow-volume relationships with particular reference to the maximum expiratory flow volume curve. Phys. in Med. Biol. 1958, 3, 174.

19. Fry, D. L., and R. E. Hyatt. Pulmonary mechanics. A unified analysis of the relationship between pressure, volume and gasflow in the lungs of normal and diseased human subjects. Amer. J. Med. 1960, 29, 672 .

20. Otis, A. B., C. B. McKerrow, R. A. Bartlett, J. Mead, M. B. McIlroy, N. J. Selverston, and E. P. Radford, Jr. Mechanical factors in the distribution of pulmonary ventilation. J. appl. Physiol. 1956, 8, 427.

21. Radford, E. P., Jr. Recent studies of mechanical properties of mammalian lungs in Tissue Elasticity, J. W. Remington, Ed. Washington, D. C., American Physiological Society, 1957.

22. Bernstein, L. The elastic pressure-volume curves of the lungs and thorax of the living rabbit. J. Physiol. (Lond.) 1957, 138, 473.

23. Ferris, B. J., Jr., and D. S. Pollard. Effect of deep and quiet breathing on pulmonary compliance in man. J. clin. Invest. 1960, 39, 143.

24. Cohn, J. E., and H. Donoso. Pulmonary ventilationperfusion relationships. Fed. Proc. 1961, 20, 421.

25. Mead, J., I. Lindgren, and E. A. Gaensler. The mechanical properties of the lungs in emphysema. J. clin. Invest. 1955, 34, 1005.

26. Mead, J. Mechanical properties of lungs. Physiol. Rev. 1961, 41, 281.

27. Cohn, J. E. Respiratory function in muscular dystrophy (abstract). Clin. Res. 1962, 10, 121.

28. Milic-Emili, J., E. Glauser, and J. Mead. Influence of esophageal elastance on V-P measurements of lungs. Fed. Proc. 1961, 20, 427.

29. Greifenstein, F. E., R. M. King, S. S. Latch, and J. H. Comroe, Jr. Pulmonary function studies in healthy men and women 50 years and older. J. appl. Physiol. 1952, 4, 641. 